Research Article

\title{
Synthesis of Magnetic Base Catalyst from Industrial Waste for Transesterification of Palm Oil
}

\author{
Shamala Gowri Krishnan ${ }^{1}$, Fei-Ling Pua ${ }^{2,3, *}$, Hong-Hua Lim ${ }^{1}$ \\ ${ }^{1}$ College of Graduate Studies, Universiti Tenaga Nasional, 43000 Kajang, Selangor, Malaysia. \\ ${ }^{2}$ Institute of Sustainable Energy, Universiti Tenaga Nasional, 43000 Kajang, Selangor, Malaysia. \\ ${ }^{3}$ Department of Mechanical Engineering, College of Engineering, Universiti Tenaga Nasional, 43000 \\ Kajang, Selangor, Malaysia.
}

Received: 30th September 2021; Revised: $18^{\text {th }}$ November 2021; Accepted: $18^{\text {th }}$ November 2021; Available online: 22 nd November 2021; Published regularly: March 2022

\section{Abstract}

Industrial waste is produced in large amounts annually; without proper planning, the waste might cause a serious threat to the environment. Hence, an industrial waste-based heterogeneous magnetic catalyst was synthesized using carbide lime waste (CLW) as raw material for biodiesel production via transesterification of palm oil. The catalyst was successfully synthesized by the one-step impregnation method and calcination at $600{ }^{\circ} \mathrm{C}$. The synthesized catalyst, $\mathrm{C}-\mathrm{CLW} / \gamma-\mathrm{Fe}_{2} \mathrm{O}_{3}$, was characterized by temperature-programmed desorption of carbon dioxide $\left(\mathrm{CO}_{2}\right.$-TPD), scanning electron microscopy (SEM), electron dispersive X-ray spectroscopy (EDX), X-ray Diffraction (XRD), Brunauer-Emmett-Teller (BET), vibrating sample magnetometer (VSM), and Fourier transform infrared spectroscopy (FT-IR). The catalyst has a specific surface area of $18.54 \mathrm{~m}^{2} / \mathrm{g}$ and high basicity of $3,637.20 \mu \mathrm{mol} / \mathrm{g}$. The catalytic performance shows that the optimum reaction conditions are $6 \mathrm{wt} \%$ catalyst loading, $12: 1$ methanol to oil molar ratio with the reaction time of $3 \mathrm{~h}$ at $60{ }^{\circ} \mathrm{C}$ to produce $90.5 \%$ biodiesel yield. The catalyst exhibits good catalytic activity and magnetism, indicating that the CLW can be a potential raw material for catalyst preparation and application in the biodiesel industry.

Copyright (C) 2021 by Authors, Published by BCREC Group. This is an open access article under the CC BY-SA License (https://creativecommons.org/licenses/by-sa/4.0).

Keywords: Carbide lime waste; Magnetic; Base catalyst; Transesterification; palm oil

How to Cite: S.G. Krishnan, F.-L. Pua, H.-H. Lim (2022). Synthesis of Magnetic Base Catalyst from Industrial Waste for Transesterification of Palm Oil. Bulletin of Chemical Reaction Engineering \& Catalysis, 17(1), 53-64 (doi: 10.9767/bcrec.17.1.12412.53-64)

Permalink/DOI: https://doi.org/10.9767/bcrec.17.1.12412.53-64

\section{Introduction}

Carbide lime is the by-product of acetylene production, largely produced every year in Malaysia [1]. Carbide Lime Waste (CLW) composed by calcium hydroxide $\left(\mathrm{Ca}\left(\mathrm{OH}_{2}\right)\right)$, calcium carbonate $\left(\mathrm{CaCO}_{3}\right)$, unreacted carbon and silicates with $\sim 85-95 \%, \sim 1-10 \%$ and $1-3 \%$, respectively [2]. CLW has been used to replace lime in the agricultural sector, road constructions,

\footnotetext{
* Corresponding Author.

Email: gracepua@uniten.edu.my (F.-L. Pua);

Telp: +603-89212020
}

wastewater treatment and other industries $[3,4]$. Since the CLW is classified as scheduled industrial waste in Malaysia, and this byproduct continues to be landfilled as solid waste, that has affected the environment. The utilization of this by-product in different fields could increase its application to preserve the environment.

Over the years, biodiesel has gained more importance as an alternative source of energy that has both environmental and health benefits than fossil fuel. Biodiesel production still demands an improvised industrial process, reduc- 
tion in production cost, and environmental benefits [5]. Biodiesel generates minimal greenhouse gases emission of carbon dioxide $\left(\mathrm{CO}_{2}\right)$, carbon monoxide (CO), unburned hydrocarbons and particulate matter to the environment; hence, biodiesel is considered renewable, biodegradable, non-toxic and sustainable [6]. It is produced from feedstock such as vegetable oils, animal or greases through conventional method, transesterification reaction with alcohol, and catalyst [7]. The catalyst selection is the most significant factor in biodiesel production.

Catalysts are categorized as homogeneous, heterogeneous, or enzymatic and are frequently employed to synthesize biodiesel. Homogeneous catalysts: sodium hydroxide $(\mathrm{NaOH})$, potassium hydroxide $(\mathrm{KOH})$ and sodium methoxide $\left(\mathrm{CH}_{3} \mathrm{ONa}\right)$ are the general catalysts reported in the transesterification process $[8,9]$. These catalysts are relatively inexpensive and widely accessible; nevertheless, they may create saponification and separation problems in the final product and lower yield [10]. Furthermore, the catalyst unable to recycle as it is difficult to recover from the reaction mixture. As a result, these issues may be overcome by replacing homogeneous catalysts with heterogeneous catalysts. Heterogeneous catalysts are recyclable and non-corrosive, which is good for the environment [11]. Heterogeneous catalysts can be cost-effective as waste resources such as ashes, shells, and bones can be potential raw materials [12]. Calcium oxide, $\mathrm{CaO}$, is the most commonly used heterogeneous catalyst in transesterification [13]. Various waste sources such as eggshells, bones, rocks with calcite and marble can be easily converted to $\mathrm{CaO}$ through the calcination process [14]. However, separation and recovery of these catalysts are still challenging for industrial-scale as it is timeconsuming.

Recently, attention was given to synthesize multifunctional heterogeneous catalysts to minimize energy consumption in the separation process and promising catalysts for the transesterification process [15]. Heterogeneous catalyst with magnetic property evades the conventional filtration problem, enable catalyst recyclability, high catalyst recovery, and decrease production time [16]. The potential of heterogeneous magnetic catalysts in the transesterification process was studied [17,18]. Ali et al. [19], prepared $\mathrm{CaO}$ supported $\mathrm{Fe}_{3} \mathrm{O}_{4}$ magnetic nanocatalyst by chemical precipitation method and reported that the highest biodiesel yield of $69.7 \%$ exhibited using palm seed oil under the optimized reaction conditions of $10 \mathrm{wt} \%$ catalyst loading and 20:1 methanol to oil molar ra- tio at $65{ }^{\circ} \mathrm{C}$ for $5 \mathrm{~h}$. Another study showed that biodiesel yield for the Stillingia oil of $95 \%$ was obtained using nanomagnetic catalyst $\mathrm{KF} / \mathrm{CaO}$ $\mathrm{Fe}_{3} \mathrm{O}_{4}$ with $4 \mathrm{wt} \%$ catalyst loading and 12:1

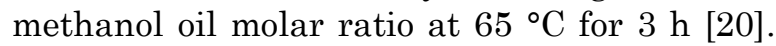
Besides, the incorporation of iron oxide $(\mathrm{Fe}-\mathrm{O})$ provides a large amount of active sites that could advantage a higher catalytic activity [21].

The present work aims to synthesize industrial waste, CLW supported magnetic base catalyst for biodiesel production. The raw CLW were calcined at a specific temperature and time to produce calcined CLW before catalyst preparation. The catalyst was synthesized by the one-step impregnation method, and the properties were characterized. The catalytic performance was measured by the transesterification of palm oil. The biodiesel yield was evaluated using a gas chromatography-flame ionization detector (GC-FID), and the ester functional groups were identified by Fourier Transform Infrared Spectrometry (FT-IR).

\section{Materials and Methods}

\subsection{Materials}

Raw carbide lime waste (CLW) is supplied by the Department of Mineral and Geoscience (Perak, Malaysia). All the chemicals used were analytical reagents; Ferric sulfate $\left(\mathrm{Fe}_{3}\left(\mathrm{SO}_{4}\right)_{2}\right)$ and ferrous sulfate heptahydrate $\left(\mathrm{FeSO}_{4} .7 \mathrm{H}_{2} \mathrm{O}\right)$ used in the catalyst preparation were purchased from Suria Pembekal Umum Sdn. Bhd (Malaysia).

\subsection{Catalyst Preparation}

Firstly, raw carbide lime waste was mortared and sieved to a homogeneous size and calcined at $850{ }^{\circ} \mathrm{C}$ for 4 hours before catalyst preparation. $0.04 \mathrm{M}$ ferric (III) sulfate $\left(\mathrm{Fe}_{2}\left(\mathrm{SO}_{4}\right)_{3}\right)$ and $0.02 \mathrm{M}$ ferrous (II) sulfate heptahydrate $\left(\mathrm{FeSO}_{4} .7 \mathrm{H}_{2} \mathrm{O}\right)$ were dissolved in 50 $\mathrm{ml}$ distilled water. $10 \mathrm{ml}$ of ammonium hydroxide was slowly added into the solution and agitated at $60^{\circ} \mathrm{C}$ for $0.5 \mathrm{~h}$ to produce black precipitates. Then, calcined CLW (5 g) was added into the mixture and stirred continuously for $2 \mathrm{~h}$. The magnetic solid was recovered using a permanent magnet, removed the excess solution and washed with ethanol. The solids were oven-dried at $60^{\circ} \mathrm{C}$ overnight.

The oven-dried sample was mortared and sieved to homogeneous size, then calcined at $600{ }^{\circ} \mathrm{C}$ for $3 \mathrm{~h}$. The synthesized catalyst was stored in a desiccator to avoid contamination and denoted as C-CLW/ $/$ - $\mathrm{Fe}_{2} \mathrm{O}_{3}$. 


\subsection{Catalyst Characterization}

The following Hammett indicators and their associated values were employed to measure the base strength of the synthesized catalyst: bromothymol blue (H_7.2), phenolphthalein (H_9.3), 2,4-dinitroaniline (H_15.0), 4nitroaniline (H_18.4), and diphenylamine $\left(\mathrm{H}_{-}\right.$ 22.3). The basic strength test was conducted by adding $10 \mathrm{ml}$ ethanoic Hammett indicators into test tubes containing $0.05 \mathrm{~g}$ of catalyst. The mixture was agitated and set idle for $30 \mathrm{mins}$, and the changes in the solution's colour were observed. The basicity of the catalyst was tested using a Thermo Finnigan TPDRO 1100 equipped with a thermal conductivity detector and temperature-programmed $\mathrm{CO}_{2}$ desorption (Universiti Putra Malaysia).

Scanning electron microscopy (SEM) with electron dispersive X-ray spectroscopy (EDX) (JSM-6010PLUS/LV, Universiti Tenaga Nasional) was used to evaluate the morphology and elemental content of the catalyst. X-ray diffraction (XRD) was used to analyze the structure and pattern of the catalyst using X'Pert Pro, PANalytical (Quantum Skynet). The average crystalline size was calculated using Debye Scherrer's equation (Equation (1)):

$$
D=\frac{0.89 \lambda}{\beta \cos \theta}
$$

where, $D$ is the average crystalline size, $\lambda$ is the wavelength $=0.154 \mathrm{~nm}, \theta$ is the diffraction angle, and $\beta$ is the line broadening at half the maximum intensity (FWHM).

Brunauer-Emmett-Teller (BET) technique was used to measure the specific surface area and pore volume by Micromeritics, Model: ASAP2020, USA (Quantum Skynet). The chemical characteristics of the catalyst were investigated using the conventional $\mathrm{KBr}$ technique at the Faculty of Science, Universiti Malaya, utilizing Fourier transform infrared spectroscopy (FT-IR; Nicolet iS10, Thermo Fisher Scientific Co., Ltd., Waltham, MA). The catalyst's magnetism was characterized by a vibrating sample magnetometer, VSM (Lake Shore 7400 Series), at Nanocat Lab, Universiti Malaya.

\subsection{Transesterification Reaction}

The transesterification study of palm oil over the C-CLW $/ \gamma-\mathrm{Fe}_{2} \mathrm{O}_{3}$ catalyst was investigated by the one-factor-at-a-time method. The catalytic performance was measured using the traditional reflux system method. $20 \mathrm{~g}$ of the palm oil with various catalyst loading (1-9 wt\%) and methanol to oil molar ratio (10:1$15: 1)$ with reaction time $(2-4 \mathrm{~h})$ were agitated at constant temperature and speed of $60{ }^{\circ} \mathrm{C}$ and $350 \mathrm{rpm}$, respectively. Following the reaction, a permanent magnet was used to separate the solid base catalyst, and the collected liquid was heated to eliminate excess methanol from the samples. Finally, the recovered catalyst was washed and oven-dried for further use.

\subsection{Product Characterization}

The fatty acid methyl ester (FAME) products were analyzed with a gas chromatography-flame ionization detector (GC-FID) to calculate the biodiesel yield using the equation (Equation (2)). The chemical characteristics of the biodiesel sample were identified by Fourier transform infrared spectroscopy (FT-IR) ranging from 4000 to $400 \mathrm{~cm}^{-1}$ at the Institute of Sustainable Energy, Universiti Tenaga Nasional.

$$
\text { Ester yield, } \%=\left(\frac{\sum A-A_{C 17 I S}}{A_{C 17 I S}} \times \frac{C_{E 1} \times V_{E 1}}{m}\right) \times 100
$$

where, $\sum_{\mathrm{A}}$ is sum of methyl esters peaks, $A_{C 17 I S}$ is internal standard $\left(\mathrm{C}_{17}\right), C_{E 1}$ is concentration of $\mathrm{C}_{17}$ solution $(\mathrm{mg} / \mathrm{mL}), V_{E 1}$ is volume of $\mathrm{C}_{17}$ solution (mL), and $m$ is weight of sample (mg).

\section{Results and Discussion}

\subsection{Base Strength Test}

The catalytic performance of the solid catalyst in the transesterification process is determined by its basic properties [22]. The base strength of the $\mathrm{C}-\mathrm{CLW} / \gamma-\mathrm{Fe}_{2} \mathrm{O}_{3}$ catalyst was analyzed using Hammett indicators and is shown in Table 1. The base strength of the synthesized magnetic solid catalyst is $18.4<\mathrm{H}_{-}<$ 22.3 , which is considered a strong solid base catalyst. Comparatively, the calcined CLW had a base strength of $7.2<\mathrm{H}_{-}<9.3$. Thus, C$\mathrm{CLW} / \gamma-\mathrm{Fe}_{2} \mathrm{O}_{3}$ catalyst potential to catalyze palm oil in the transesterification process.

\subsection{Temperature-Programmed Desorption of Carbon Dioxide $\left(\mathrm{CO}_{2}\right.$-TPD) Analysis}

The basic strength of the C-CLW/ $\gamma-\mathrm{Fe}_{2} \mathrm{O}_{3}$ catalyst was evaluated through $\mathrm{CO}_{2}$-TPD analysis. Figure 1 illustrates the basicity profile of the synthesized catalyst. According to the pro-

Table 1. Base strength test of C-CLW/ $\gamma-\mathrm{Fe}_{2} \mathrm{O}_{3}$ catalyst.

\begin{tabular}{lc}
\hline Sample & Basic strength $\left(\mathrm{H}_{-}\right)$ \\
\hline Calcined $\mathrm{CLW}$ & $7.2<\mathrm{H}_{-}<9.3$ \\
$\mathrm{C}-\mathrm{CLW} / \gamma-\mathrm{Fe}_{2} \mathrm{O}_{3}$ & $18.4<\mathrm{H}_{-}<22.3$ \\
\hline
\end{tabular}


file of $\mathrm{CO}_{2}$ desorption, the catalyst exhibited strong basicity with $\mathrm{T}_{\max }>700{ }^{\circ} \mathrm{C}$, where the desorption peak of $\mathrm{C}$-CLW/Y- $-\mathrm{Fe}_{2} \mathrm{O}_{3}$ catalyst was at $768{ }^{\circ} \mathrm{C}(3,637.20 \mu \mathrm{mol} / \mathrm{g})$. This peak was attributed to the $\mathrm{CO}_{2}$ desorption and its interaction with the strong basic sites. It was mentioned that the narrow peak at hightemperature $600-850{ }^{\circ} \mathrm{C}$ indicates the catalyst

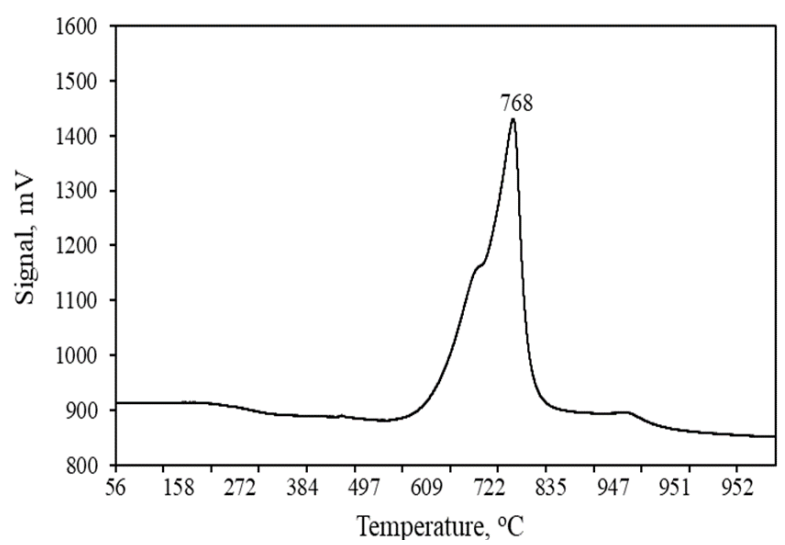

Figure 1. $\mathrm{CO}_{2}$-TPD profile of C-CLW/ $\gamma-\mathrm{Fe}_{2} \mathrm{O}_{3}$ catalyst. has strong basic sites [23]. $\mathrm{CaO}$, the highly basic oxide, was found on the surface of the catalyst [24]. Meanwhile, the calcined CLW possessed basicity of $88.44 \mu \mathrm{mol} / \mathrm{g}$. The result proved that the synthesized catalyst had strong basic sites, corresponding to the base strength test via Hammett indicator and appropriate for use as a base catalyst in the transesterification reaction.

3.3 Morphology and Elemental Composition Analyses

SEM micrographs of $\mathrm{C}-\mathrm{CLW} / \gamma-\mathrm{Fe}_{2} \mathrm{O}_{3}$ catalyst after calcination is shown in Figure 2(a). The image at low magnification (1000x) shows that the particles are irregularly distributed with crystal formation on the calcined CLW. According to Widayat et al. [25], $\mathrm{CaO}$ particles formed crystal-like structures on the catalyst surface. While, at high magnification (2500x), the particles are seen to be in encapsulated structure. The result shows that an agglomerated structure was formed successfully between the calcined CLW and $\gamma-\mathrm{Fe}_{2} \mathrm{O}_{3}$ after cal-

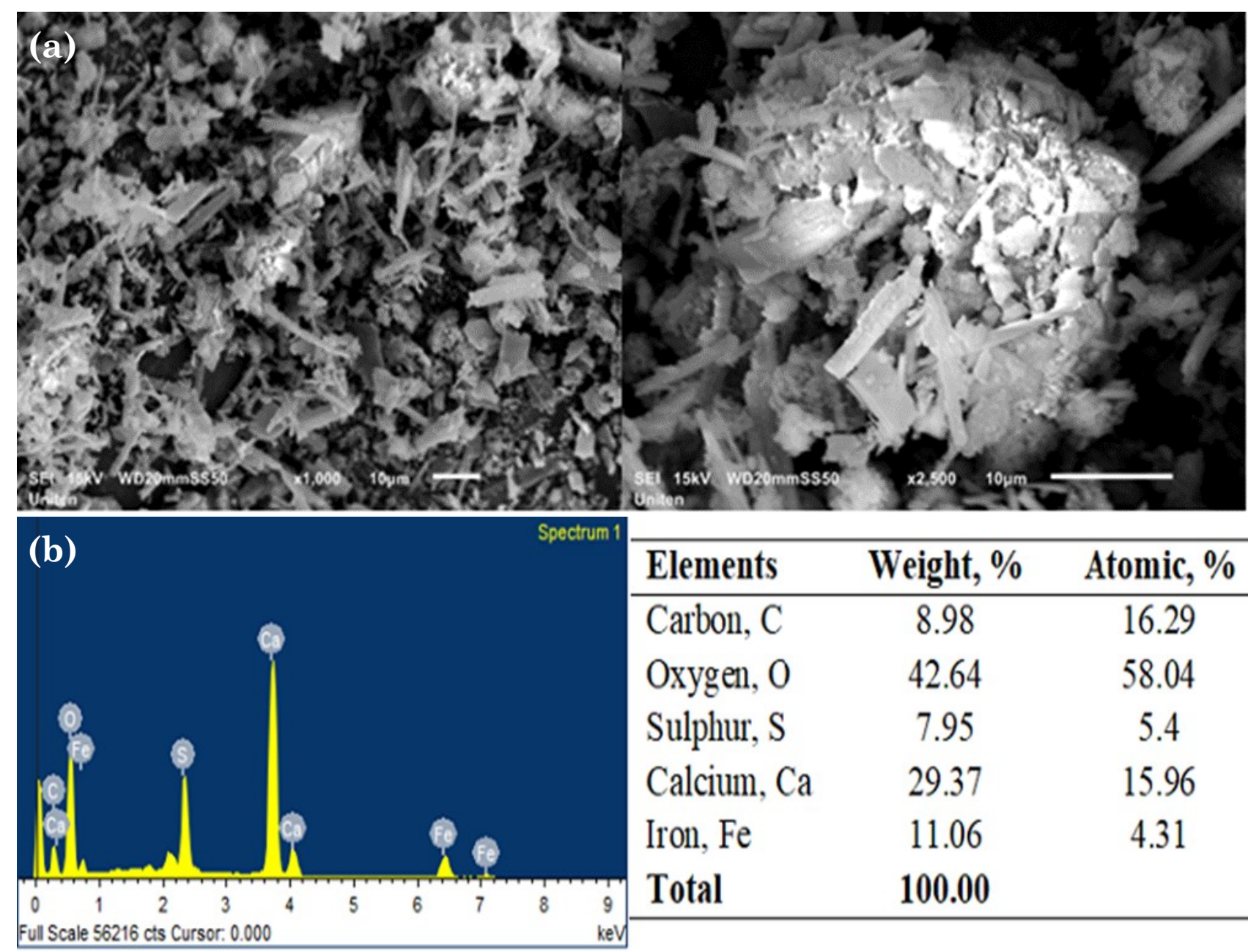

Figure 2. (a) SEM images and (b) EDX spectrum of C-CLW/ $\gamma-\mathrm{Fe}_{2} \mathrm{O}_{3}$ catalyst. 
cination. The presence of metal content was validated by EDX analysis (Figure 2(b)). The catalyst has high compositions of $\mathrm{Ca}$ and $\mathrm{O}$ followed by $\mathrm{Fe}$ on the surface with 29.37 wt\%, $42.26 \mathrm{wt} \%$ and $11.06 \mathrm{wt} \%$, respectively. Besides, a lower composition of $\mathrm{C}$ and $\mathrm{S}$ with 8.98 wt $\%$ and 7.95 wt\%, respectively were identified in the catalyst surface. Based on the EDX results, the stoichiometry values of $\mathrm{Fe}, \mathrm{Ca}$, and $\mathrm{O}$ are detected. The catalyst mainly consisted of Fe-based $\mathrm{CaO}$ and $\mathrm{CaO}$ with a $\mathrm{Fe} / \mathrm{Ca} / \mathrm{O}$ molar ratio of 1.00/3.70/13.47. It was reported by Sun et al. that the $\mathrm{Ca}_{2} \mathrm{Fe}_{2} \mathrm{O}_{5}$ catalyst has mainly composed of calcium and iron, which was determined by EDX analysis [26].

\subsection{Structural Analysis}

The structural properties of the synthesized $\mathrm{C}-\mathrm{CLW} / \gamma-\mathrm{Fe}_{2} \mathrm{O}_{3}$ catalyst are identified by XRD analysis, as shown in Figure 3. The pattern showed broad diffraction peaks of $2 \theta$ at the range of $15-65^{\circ}$ and the diffractogram composed of maghemite, $\gamma-\mathrm{Fe}_{2} \mathrm{O}_{3}$ and calcium oxide, $\mathrm{CaO}$ diffraction peaks. The compounds are assigned according to the Inorganic Crystal Structure Database, where the $\gamma-\mathrm{Fe}_{2} \mathrm{O}_{3}$ compound is associated with ICSD Card: 98-0117730 and $\mathrm{CaO}$ with ICSD Card: 98-005-7267. The peaks corresponding to $2 \theta$ value of $\gamma-\mathrm{Fe}_{2} \mathrm{O}_{3}$ identified at $18.1^{\circ}(111), 25.6^{\circ}(112), 29.5^{\circ}(022)$, $31.5^{\circ}(122), 34.2^{\circ}(113), 38.8^{\circ}(023), 47.3^{\circ}(024)$, $48.9^{\circ}(124), 52.5^{\circ}(224), 54.6^{\circ}(015), 55.9^{\circ}(115)$, and $62.7^{\circ}(144)$, which are associated with cubic shape. The active phase of cubic $\mathrm{CaO}$ was also identified in the region $2 \theta: 31.5^{\circ}$ (111), $38.8^{\circ}(002)$, and $54.6^{\circ}(022)$. The results were in agreement with the stoichiometry values suggested from EDX analysis. The particle size of the C-CLW/ $\gamma-\mathrm{Fe}_{2} \mathrm{O}_{3}$ catalyst was calculated to be $17.59 \mathrm{~nm}$ and indicated high crystalline degrees. According to Kholkina et al. [27], the for-

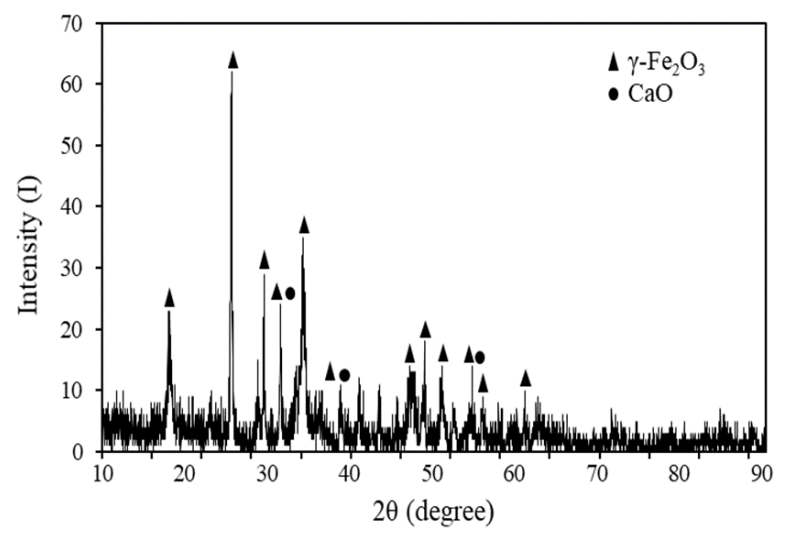

Figure 3. XRD pattern of C-CLW/ $\gamma-\mathrm{Fe}_{2} \mathrm{O}_{3}$ catalyst. mation of clusters corresponded to small particle size and a high degree of crystallinity.

\subsection{Specific Surface Area Analysis}

BET analysis was used to investigate the specific surface area, pore-volume, and pore size at liquid $\mathrm{N}_{2}$ temperature $\left(-196{ }^{\circ} \mathrm{C}\right)$, as shown in Figure 4. The C-CLW/ $\gamma-\mathrm{Fe}_{2} \mathrm{O}_{3}$ catalyst exhibited BET specific surface area of $18.54 \mathrm{~m}^{2} / \mathrm{g}$ with a pore volume of $0.142 \mathrm{~cm}^{3} / \mathrm{g}$ and average pore size of $30.77 \mathrm{~nm}$. The pore size, pore-volume, and specific surface area were essential factors for the catalyst's catalytic efficacy [28]. Based on the pore size distribution, the catalyst exhibited mesoporous particles. Therefore, this result shows that the catalyst's pore size could allow the accessibility of reactants with active sites in the catalyst, which enhance the catalytic reaction between triglyceride and alcohol and provide a higher yield [29]. Maneerung et al. [30] observed that the bottom ash-derived $\mathrm{CaO}$ catalyst had a lower specific surface area of $8.98 \mathrm{~m}^{2} / \mathrm{g}$ and pore volume of $0.0621 \mathrm{~cm}^{3} / \mathrm{g}$ after calcination at $800{ }^{\circ} \mathrm{C}$. Hence, the $\mathrm{C}-\mathrm{CLW} / \gamma-\mathrm{Fe}_{2} \mathrm{O}_{3}$ catalyst calcined at $600{ }^{\circ} \mathrm{C}$ was suitable to exhibit the catalyst's catalytic performance.

\subsection{Magnetism Analysis}

Figure 5 presents the magnetic characteristic of the C-CLW/ $\gamma-\mathrm{Fe}_{2} \mathrm{O}_{3}$ catalyst determined by VSM analysis in the field range $\pm 10 \mathrm{kOe}$. Theoretically, the $\gamma-\mathrm{Fe}_{2} \mathrm{O}_{3}$ has a saturation magnetization value of about $40 \mathrm{emu} / \mathrm{g}$ [31], and it was noticed that the value reduced to $6.61 \mathrm{emu} / \mathrm{g}$ during the catalyst preparation. It might be due to changes in the interface structure of the catalyst, which cause the magnetization value to decrease [32]. Besides, the catalyst's low magnetization could be due to the in-

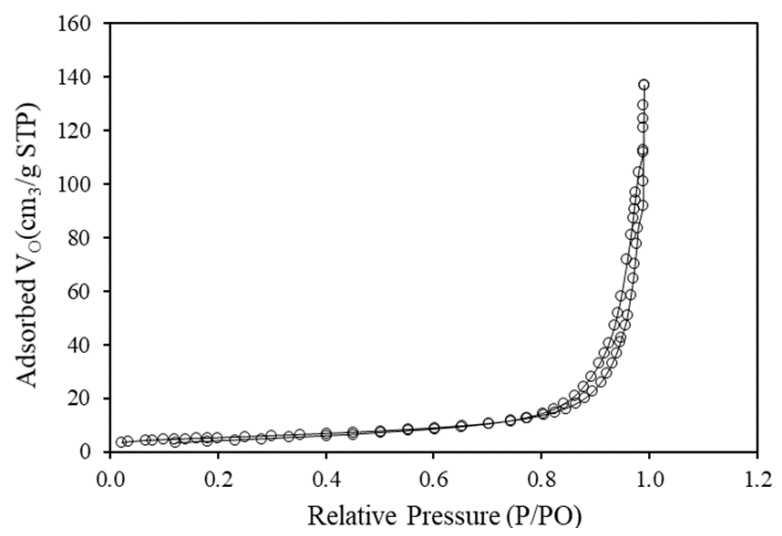

Figure 4. $\mathrm{N}_{2}$ adsorption-desorption of C-CLW/ $\mathrm{Fe}_{2} \mathrm{O}_{3}$ catalyst. 
corporation of $\gamma-\mathrm{Fe}_{2} \mathrm{O}_{3}$ with calcined CLW during the process. It is likely related to the SEM analysis, where the particles are present in clusters on the surface. Tang et al. [33] mentioned that the magnetism of magnetic base catalyst, $\mathrm{Ca} / \mathrm{Al} / \mathrm{Fe}_{3} \mathrm{O}_{4}$ composite catalyst dropped to $6.34 \mathrm{emu} / \mathrm{g}$ after adding metals into the $\mathrm{Fe}_{3} \mathrm{O}_{4}$ solution. Junior et al. [34] reported that the magnetization value dropped during the catalyst preparation was due to the incorporation of maghemite in the monoliths. The monolithic magnetic catalyst had $5.73 \mathrm{emu} / \mathrm{g}$, which reduced from $32.57 \mathrm{emu} / \mathrm{g}$. Although low magnetization, the catalyst was still efficiently removed from the reaction using an external magnet.

\subsection{Chemical Analysis}

The functional groups in the synthesized C$\mathrm{CLW} / \gamma-\mathrm{Fe}_{2} \mathrm{O}_{3}$ catalyst were characterized using FT-IR analysis (Figure 6). The absorption bands at $3641 \mathrm{~cm}^{-1}$ and $675 \mathrm{~cm}^{-1}$ correspond to the hydroxyl group, $\mathrm{O}-\mathrm{H}$ stretching, which might be ascribed to the $\mathrm{H}_{2} \mathrm{O}$ on the catalyst surface. The bands detected at $1447 \mathrm{~cm}^{-1}$ might be attributed to carbonate $\mathrm{CO}_{3^{2-}}$ of $\mathrm{C}-\mathrm{O}$ stretching on the catalyst surface [35]. The interaction between catalysts' active sites with the atmosphere could be the reason for $\mathrm{CO}_{3}{ }^{2-}$ formation. Meanwhile, a significant absorption band was detected at $1151 \mathrm{~cm}^{-1}$, demonstrating the hydroxyl functional group in the catalyst [36]. A weak vibration band at around $878 \mathrm{~cm}^{-1}$ was assigned to the $\mathrm{Ca}-\mathrm{O}$ bonds [37], which was according to the XRD and EDX results. The peak at $595 \mathrm{~cm}^{-1}$ corresponds to the $\mathrm{Fe}-\mathrm{O}$ stretching vibration of the $\gamma-\mathrm{Fe}_{2} \mathrm{O}_{3}$ found in the catalyst [38].

\subsection{Effects of Reaction Parameters on Trans- esterification Reaction}

As shown in Figure $7(\mathrm{a}-\mathrm{c})$, the influence of independent factors such as catalyst loading, methanol to oil molar ratio, and reaction time on the transesterification reaction was studied. The synthesis of fatty acid methyl ester (FAME) from palm oil was investigated using these main factors. The transesterification process was carried out at $60^{\circ} \mathrm{C}$ for $2 \mathrm{~h}$ with various catalyst loadings (1-9 wt\%) and a 10:1 methanol to oil molar ratio. Catalyst enhances the biodiesel production yield by interacting with the methanol to form methoxide oil, which helps break down the fatty acids in the oil to produce FAME. According to Figure 7(a), the biodiesel yield increased as the catalyst loading increased. At $1 \mathrm{wt} \%$ catalyst loading, a yield of

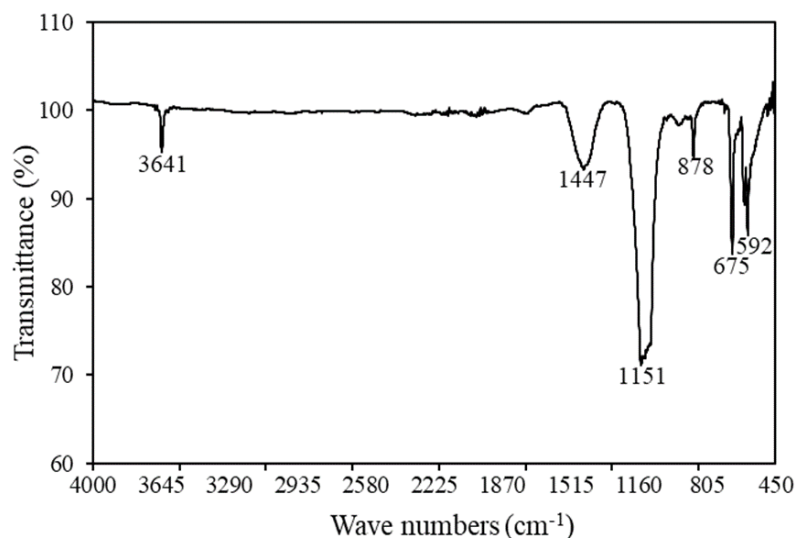

Figure 6. FT-IR spectrum of C-CLW/ $\gamma-\mathrm{Fe}_{2} \mathrm{O}_{3}$ catalyst.
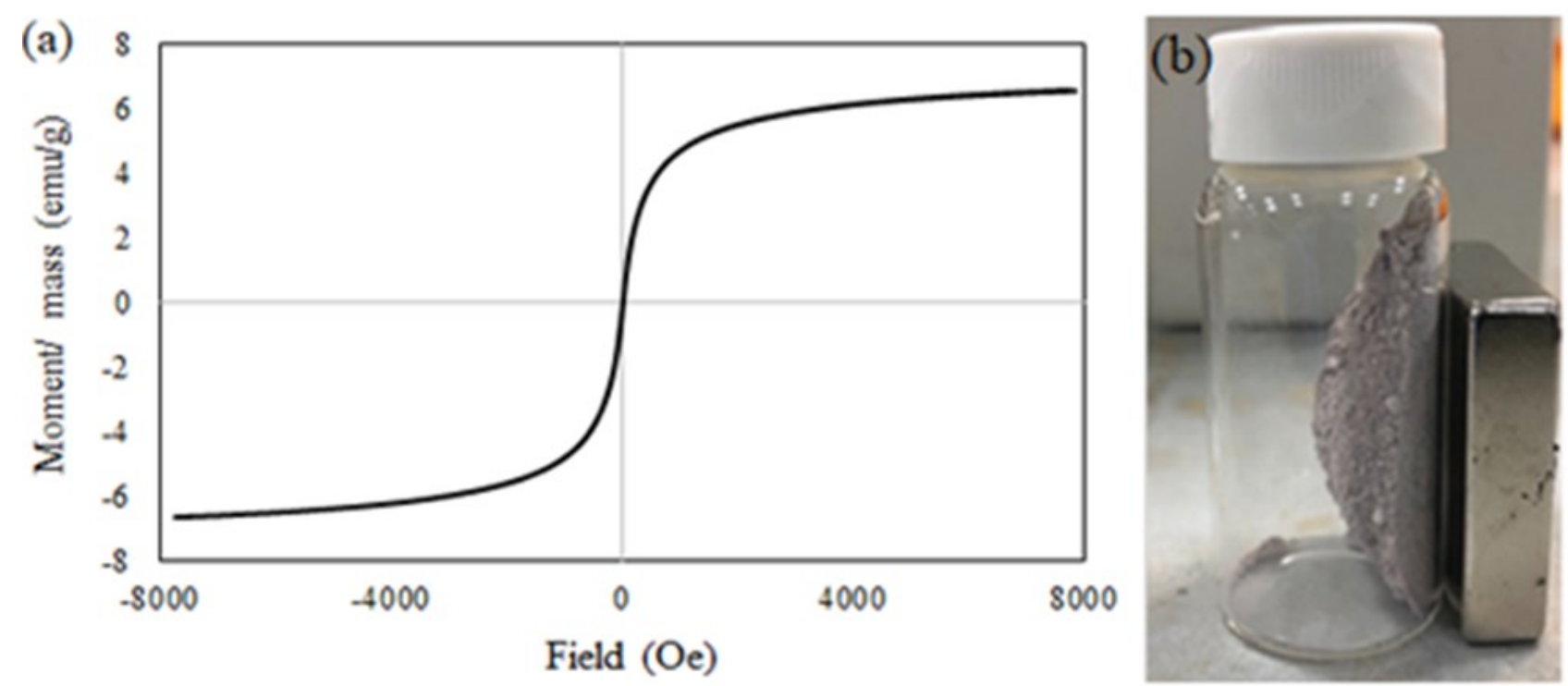

Figure 5. (a) VSM magnetization curve and (b) magnetic separation of $\mathrm{C}-\mathrm{CLW} / \gamma-\mathrm{Fe}_{2} \mathrm{O}_{3}$ catalyst. 
$74.1 \%$ was obtained and increased to $85.5 \%$ at $6 \mathrm{wt} \%$. However, a further increase in the catalyst loading decreases the biodiesel yield from $85.5 \%$ to $82.8 \%$ (9 wt\%). It might be related to reactants-catalyst mixing since increased catalyst loading generates high viscosity with a limited amount to react, lowering the yield [39]. Hence, $6 \mathrm{wt} \%$ catalyst loading was optimum to provide a higher biodiesel yield.
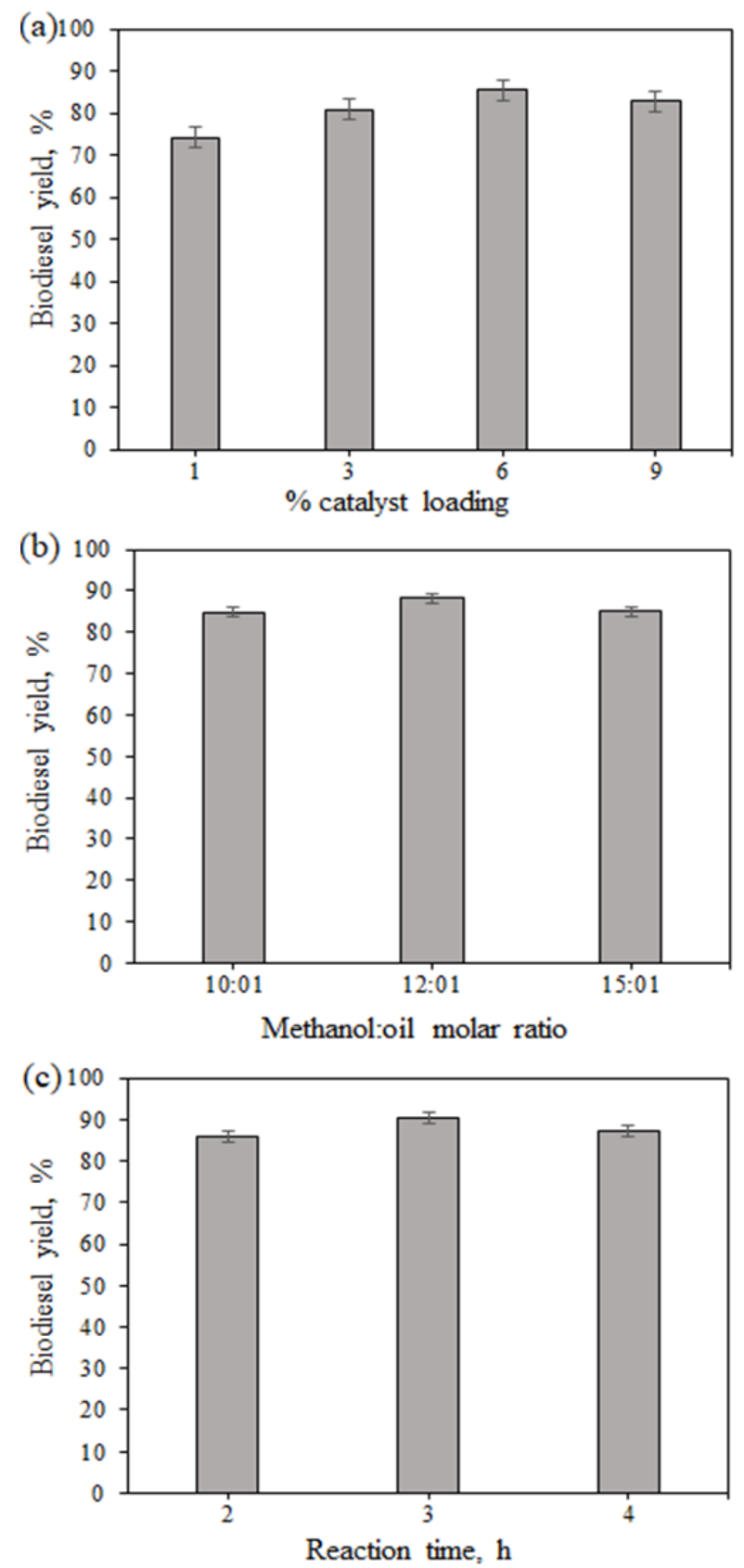

Figure 7. The influence of reaction parameter on transesterification of palm oil (a) catalyst loading (10:1 methanol to oil molar ratio, $60^{\circ} \mathrm{C}$, $2 \mathrm{~h}$ ), (b) methanol to oil molar ratio (6 wt\% catalyst loading, $60{ }^{\circ} \mathrm{C}, 2 \mathrm{~h}$ ), and reaction time (12:1 methanol to oil molar ratio, $6 \mathrm{wt} \%$ catalyst loading, $60^{\circ} \mathrm{C}$ ).
In theory, a transesterification reaction is an equilibrium reaction that requires a larger quantity of alcohol to shift the process toward biodiesel synthesis [40]. The effect of methanol to oil molar ratio $(10: 1-15: 1)$ on transesterification reaction was studied with $6 \mathrm{wt} \%$ catalyst loading at $60{ }^{\circ} \mathrm{C}$ for $2 \mathrm{~h}$. Figure 7(b) shows that the biodiesel yield increased from $84.9 \%$ to $88.3 \%$ as the methanol to oil molar ratio increased from 10:1 to 12:1. The yield was observed to be decreased as the molar ratio increased. It was due to a large amount of methanol and weak interaction with the catalyst. A high yield may necessitate a longer reaction time. Hence, the 12:1 methanol to oil molar ratio was chosen as the best parameter from the optimization study for a better yield. As the molar ratio increased, the yield was found to be lower.

The effect of reaction time $(2-4 \mathrm{~h})$ on palm oil transesterification was investigated at 60 ${ }^{\circ} \mathrm{C}$ using a 12:1 methanol to oil molar ratio and a $6 \mathrm{wt} \%$ catalyst loading. As presented in Figure $7(\mathrm{c})$, after $2 \mathrm{~h}$ of reaction, the biodiesel production reached $85.9 \%$, and after $3 \mathrm{~h}$, the yield increased to $90.5 \%$. However, it was observed that yield has slightly reduced to $87.3 \%$ at $4 \mathrm{~h}$ of reaction time and exhibited that $3 \mathrm{~h}$ reaction time has the maximum yield. The reaction time for biodiesel production is generally longer; for instance, 6 hours of reaction time over bottom ash derived $\mathrm{CaO}$ consumed more time to produce biodiesel [30]. This study suggests that $3 \mathrm{~h}$ reaction time had considered optimum to produce biodiesel. Overall, it was discovered that the $\mathrm{C}-\mathrm{CLW} / \gamma-\mathrm{Fe}_{2} \mathrm{O}_{3}$ catalyst has a high potential for providing a higher yield at the optimized reaction parameters of $6 \mathrm{wt} \%$ catalyst loading, 12:1 methanol to oil molar ratio, and $60{ }^{\circ} \mathrm{C}$ reaction temperature for $3 \mathrm{~h}$, resulting in a higher yield of $90.5 \%$ from palm oil transesterification.

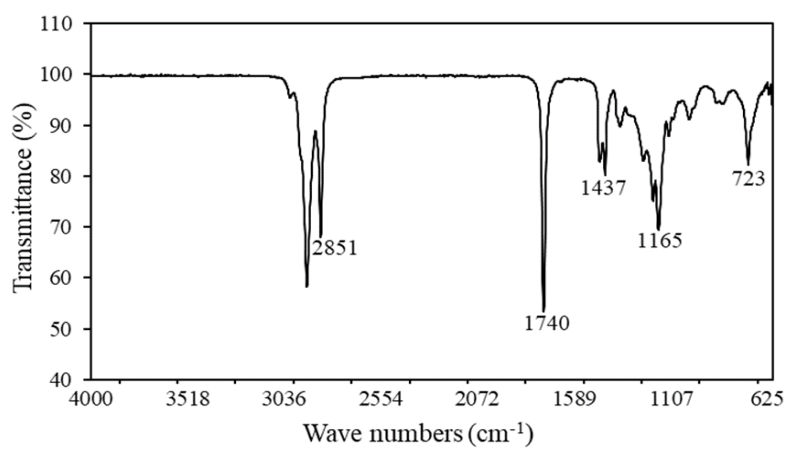

Figure 8. FT-IR spectrum of palm biodiesel. 


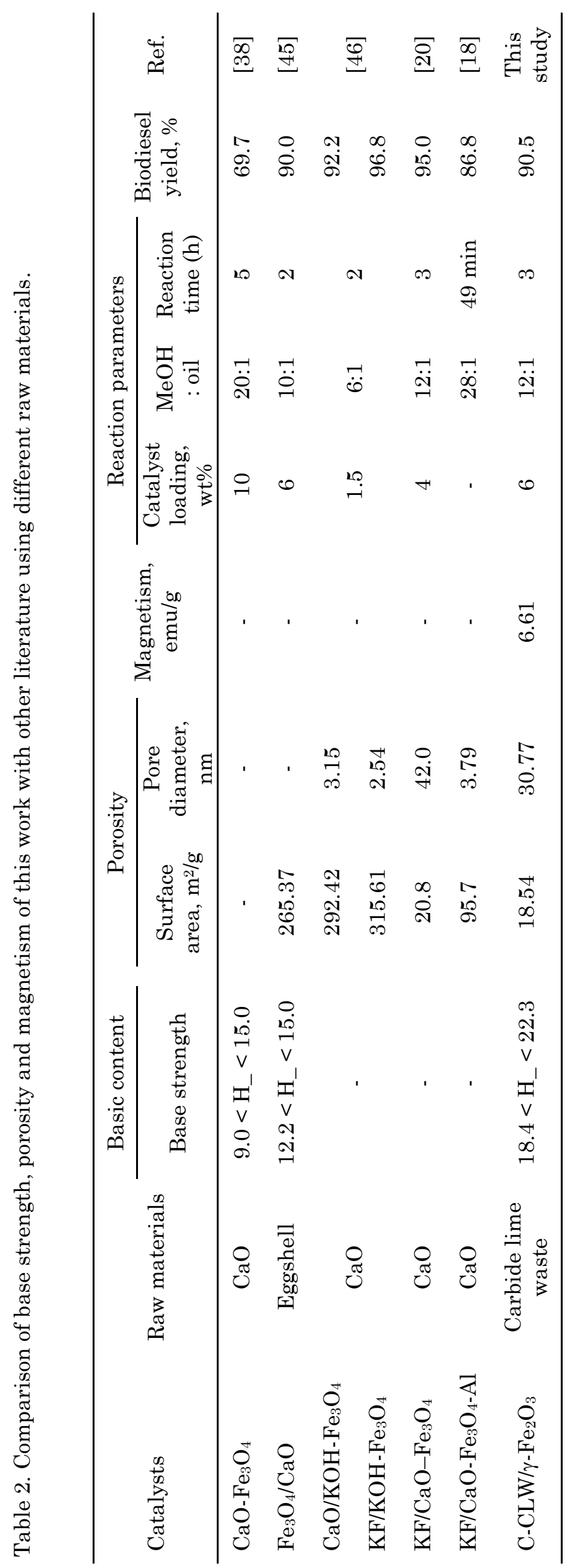




\subsection{Characterization of Methyl Esters}

Figure 8 illustrates the FT-IR spectra of the esterified sample. The FT-IR analysis was performed to determine the ester group in the highest biodiesel yield sample. The absorption bands at 2924 and $2851 \mathrm{~cm}^{-1}$ were assigned to the $\mathrm{CH}_{2}$ and $\mathrm{C}-\mathrm{H}$ asymmetric stretching vibration [41], respectively, whilst a sharp absorption band indicated the methoxy ester carbonyl group in the biodiesel at $1740 \mathrm{~cm}^{-1}$ [42]. Meanwhile, the bending vibration of the methyl group was found at the absorption band 1437 $\mathrm{cm}^{-1}$ [43] and $\mathrm{C}-\mathrm{O}$ stretching vibration at 1165 $\mathrm{cm}^{-1}$, which shows the existence of fatty acid esters in the sample [41]. Besides, methylene $-\mathrm{CH}_{2}-$, appeared at $723 \mathrm{~cm}^{-1}$, where two carbonyl groups are bridged with hydrogen atoms [44]. The result suggests that the $\mathrm{C}-\mathrm{CLW} / \gamma-\mathrm{Fe}_{2} \mathrm{O}_{3}$ catalyst has economic and environmental viability as the catalyst was produced from industrial waste. Besides, it also has good catalytic characteristics and can be magnetically separated from the reaction mixture.

3.10 Comparison of Physiochemical Characterizes of Magnetic Base Catalysts

The comparison of basic content, porosity and magnetism of magnetic base catalysts on biodiesel yields of this work and literature were shown in Table 2. It shows that the $\mathrm{C}-\mathrm{CLW} / \gamma-\mathrm{Fe}_{2} \mathrm{O}_{3}$ catalyst prepared from carbide lime waste is comparable with other catalysts and exhibited better basicity and magnetism with high yield. According to the literature, the magnetic catalyst prepared in this work has better physiochemical characteristics than other literature reported. A comparable biodiesel yield could be expected under a moderate reaction temperature or shorter reaction by using a $\mathrm{C}-\mathrm{CLW} / \gamma-\mathrm{Fe}_{2} \mathrm{O}_{3}$ catalyst. This indicates that industrial waste-derived magnetic base catalysts can be promising catalysts in biodiesel production.

\section{Conclusion}

A new magnetic solid base catalyst via carbide lime waste was synthesized using a onestep impregnation method. Based on the catalyst characterization results, the catalyst has high basicity, high surface area and pore size to allow better interaction between reactants and catalyst to produce a high yield. The optimal transesterification reaction parameters of 6 wt $\%$ catalyst loading and a 12:1 methanol-to-oil molar ratio with a $3 \mathrm{~h}$ reaction time at $60{ }^{\circ} \mathrm{C}$ generated $90.5 \%$ biodiesel yield. The used catalyst was magnetically recovered from the reaction medium using a permanent magnet. This study indicates the potential to utilize industrial waste, carbide lime waste in biodiesel production to minimize waste generation and provide a new solution for Malaysia's industrial waste.

\section{Acknowledgements}

The authors are grateful for the financial support provided by the Ministry of Higher Education (MoHE), Fundamental Research Grant Scheme (FRGS/1/2018/STG07/UNITEN/02/3) and the raw materials provided by the Mineral Research Centre, Rock Based Technology Section, Department of Mineral and Geoscience Malaysia. We also appreciate the support and facilities provided by the College of Engineering and the UNITEN Institute of Sustainable Energy.

\section{References}

[1] Othman, R., Isa, N., Othman, A. (2015). Precipitated Calcium Carbonate from Industrial Waste for Paper Making. Sains Malaysiana, 44, 1561-1565.

[2] Lam, S.M., Sin, J.C. (2019). Investigation of By-products from Acetylene Manufacturing for Acid Mine Drainage Remediation. Mine Water Environ., 38, 757-766. DOI: 10.1007/s10230-019-00640-2

[3] Ayeche, R., Hamdaoui, O. (2012). Valorization of carbide lime waste, a by-product of acetylene manufacture, in wastewater treatment. Desalin. Water Treat., 50, 87-94. DOI: 10.1080/19443994.2012.708547

[4] Chindaprasirt, P., Kampala, A., Jitsangiam, P., Horpibulsuk, S. (2020). Performance and evaluation of calcium carbide residue stabilized lateritic soil for construction materials. Case Stud. Constr. Mater., 13, e00389. DOI: 10.1016/j.cscm.2020.e00389

[5] Gebremariam, S.N., Marchetti, J.M. (2018). Economics of biodiesel production: Review. Energy Convers. Manag., 168, 74-84. DOI: 10.1016/j.enconman.2018.05.002

[6] Ashok, B., Nanthagopal, K., Sakthi Vignesh, D. (2018). Calophyllum inophyllum methyl ester biodiesel blend as an alternate fuel for diesel engine applications. Alexandria Eng. J., $\quad 57, \quad 1239-1247$. D O I : 10.1016/j.aej.2017.03.042 
[7] Jayakumar, S., Yusoff, M.M., Rahim, M.H.A., Maniam, G.P., Govindan, N. (2017). The prospect of microalgal biodiesel using agroindustrial and industrial wastes in Malaysia. Renew. Sustain. Energy Rev., 72, 33-47. DOI: 10.1016/j.rser.2017.01.002

[8] Atadashi, I.M., Aroua, M.K., Abdul Aziz, A.R., Sulaiman, N.M.N. (2013). The effects of catalysts in biodiesel production: A review. J. Ind. Eng. Chem., 19, 14-26. DOI: 10.1016/j.jiec.2012.07.009

[9] Chiang, C.L., Lin, K.S., Shu, C.W., Wu, J.C.S., Wu, K.C.W., Huang, Y.T. (2020). Enhancement of biodiesel production via sequential esterification/transesterification over solid superacidic and superbasic catalysts. Catal. Today, 348, 257-269. DOI: 10.1016/j.cattod.2019.09.037

[10] Ong, H.R., Khan, M.R., Chowdhury, M.N.K., Yousuf, A., Cheng, C.K. (2014). Synthesis and characterization of $\mathrm{CuO} / \mathrm{C}$ catalyst for the esterification of free fatty acid in rubber seed oil. Fuel, 120, 195-201. DOI: 10.1016/j.fuel.2013.12.015

[11] Neumann, K., Werth, K., Martín, A., Górak, A. (2016). Biodiesel production from waste cooking oils through esterification: Catalyst screening, chemical equilibrium and reaction kinetics. Chem. Eng. Res. Des., 107, 52-62. DOI: 10.1016/j.cherd.2015.11.008

[12] Marwaha, A., Rosha, P., Mohapatra, S.K., Mahla, S.K., Dhir, A. (2018). Waste materials as potential catalysts for biodiesel production: Current state and future scope. Fuel Process. Technol., $181, \quad 175-186$. DOI: 10.1016/j.fuproc.2018.09.011

[13] Pandit, P.R., Fulekar, M.H. (2019). Biodiesel production from microalgal biomass using $\mathrm{CaO}$ catalyst synthesized from natural waste material. Renew. Energy, 136, 837-845. DOI: 10.1016/j.renene.2019.01.047

[14] Bet-Moushoul, E., Farhadi, K., Mansourpanah, Y., Nikbakht, A.M., Molaei, R., Forough, M. (2016). Application of CaObased/Au nanoparticles as heterogeneous nanocatalysts in biodiesel production. Fuel, 164, 119-127. DOI: 10.1016/j.fuel.2015.09.067

[15] Faruque, M.O., Razzak, S.A., Hossain, M.M. (2020). Application of heterogeneous catalysts for biodiesel production from microalgal oil-a review. Catalysts, 10, 1025. DOI: 10.3390/catal10091025

[16] Chen, M.N., Mo, L.P., Cui, Z.S., Zhang, Z.H. (2019). Magnetic nanocatalysts: Synthesis and application in multicomponent reactions. Curr. Opin. Green Sustain. Chem., 15, 27-37. DOI: $10.1016 /$ j.cogsc.2018.08.009
[17] Chang, K.L., Lin, Y.C., Jhang, S.R., Cheng, W.L., Chen, S.C., Mao, S.Y. (2017). Rapid jatropha-castor biodiesel production with microwave heating and a heterogeneous base catalyst nano- $\mathrm{Ca}(\mathrm{Oh})_{2} / \mathrm{Fe}_{3} \mathrm{O}_{4}$. Catalysts, 7, 203. DOI: $10.3390 /$ catal7070203

[18] Winoto, V., Yoswathana, N. (2019). Optimization of biodiesel production using nanomagnetic CaO-based catalysts with subcritical methanol transesterification of rubber seed oil. Energies, 12(2), 230. DOI: 10.3390/en12020230

[19] Ali, R.M., Elkatory, M.R., Hamad, H.A. (2020). Highly active and stable magnetically recyclable $\mathrm{CuFe}_{2} \mathrm{O}_{4}$ as a heterogenous catalyst for efficient conversion of waste frying oil to biodiesel. Fuel, 268, 117297. DOI: 10.1016/j.fuel.2020.117297

[20] Hu, S., Guan, Y., Wang, Y., Han, H. (2011). Nano-magnetic catalyst $\mathrm{KF} / \mathrm{CaO}-\mathrm{Fe}_{3} \mathrm{O}_{4}$ for biodiesel production. Appl. Energy, 88, 26852690. DOI: 10.1016/j.apenergy.2011.02.012

[21] Dai, Y.M., Wang, Y.F., Chen, C.C. (2018). Synthesis and characterization of magnetic $\mathrm{LiFe}_{5} \mathrm{O}_{8}-\mathrm{LiFeO}_{2}$ as a solid basic catalyst for biodiesel production. Catal. Commun., 106, 20-24. DOI: 10.1016/j.catcom.2017.12.002

[22] Abdullah, S.H.Y.S., Hanapi, N.H.M., Azid, A., Umar, R., Juahir, H., Khatoon, H., Endut, A. (2017). A review of biomass-derived heterogeneous catalyst for a sustainable biodiesel production. Renew. Sustain. Energy Rev., 70, 1040-1051. DOI: 10.1016/j.rser.2016.12.008

[23] Klinklom, P., Luengnaruemitchai, A., Jai-in, S. (2013). Effect of Catalyst preparation on the Performance of $\mathrm{CaO}-\mathrm{ZnO}$ Catalyst for Transesterification. Int. Sch. Sci. Reseach Innov., $7, \quad 218-223$. D O I : 10.5281/zenodo.1070957

[24] Hamzah, N., Yusof, I., Samad, W.Z., Hamid, H.A.A., Tajuddin, N.A., Ibrahim, M.L. (2021). Calcium oxide derived from egg shells: A low cost catalyst for biodiesel production. Malaysian J. Chem., 23, 11-18.

[25] Widayat, W., Darmawan, T., Hadiyanto, H., Rosyid, R. A. (2017). Preparation of Heterogeneous CaO Catalysts for Biodiesel Production. J. Phys. Conf. Ser., 877, 8-15. DOI: 10.1088/1742-6596/877/1/012018

[26] Sun, Z., Chen, S., Russell, C.K., Hu, J., Rony, A.H., Tan, G., Chen, A., Duan, L., Boman, J., Tang, J., Chien, T.Y., Fan, M., Xiang, W. (2018). Improvement of $\mathrm{H}_{2}$-rich gas production with tar abatement from pine wood conversion over bi-functional $\mathrm{Ca}_{2} \mathrm{Fe}_{2} \mathrm{O}_{5}$ catalyst: Investigation of inner-looping redox reaction and promoting mechanisms. Appl. Energy, $212, \quad 931-943 . \quad$ D O I : 10.1016/j.apenergy.2017.12.087 
[27] Kholkina, E., Kumar, N., Ohra-aho, T., Lehtonen, J., Lindfors, C., Perula, M., Peltonen, J., Salonen, J., Murzin, D.Y. (2019). Synthesis and Characterization of Novel Catalytic Materials Using Industrial Slag: Influence of Alkaline Pretreatment, Synthesis Time and Temperature. Top. Catal., 62, 738-751. DOI: 10.1007/s11244-019-01162-5

[28] Dantas, J., Leal, E., Cornejo, D.R., Kiminami, R.H.G.A., Costa, A.C.F.M. (2018). Biodiesel production evaluating the use and reuse of magnetic nanocatalysts $\mathrm{Ni}_{0.5} \mathrm{Zn}_{0.5} \mathrm{Fe}_{2} \mathrm{O}_{4}$ synthesized in pilot-scale. Arab. J. Chem., 13, 3026-3042. DOI: 10.1016/j.arabjc.2018.08.012

[29] Jing, J.Y., Zhang, Z.Y., Wang, S.D., Li, W.Y. (2018). Influence of calcination temperature on the structure and catalytic reforming performance of $\mathrm{Ni} / \mathrm{CaO}-\mathrm{Al}_{2} \mathrm{O}_{3}$ catalyst. Ranliao Huaxue Xuebao/Journal Fuel Chem. Technol., 46, 673-679. DOI: 10.1016/s18725813(18)30030-6

[30] Maneerung, T., Kawi, S., Wang, C.H. (2015). Biomass gasification bottom ash as a source of $\mathrm{CaO}$ catalyst for biodiesel production via transesterification of palm oil. Energy Convers. Manag., 92, 234-243. DOI: 10.1016/j.enconman.2014.12.057

[31] Shi, M., Zhang, P., Fan, M., Jiang, P., Dong, Y. (2017). Influence of crystal of $\mathrm{Fe}_{2} \mathrm{O}_{3}$ in magnetism and activity of nanoparticle $\mathrm{CaO} @ \mathrm{Fe}_{2} \mathrm{O}_{3}$ for biodiesel production. Fuel, 197, 343-347. DOI: 10.1016/j.fuel.2017.02.060

[32] Ibrahim, N.A., Rashid, U., Taufiq-Yap, Y.H., Yaw, T.C.S., Ismail, I. (2019). Synthesis of carbonaceous solid acid magnetic catalyst from empty fruit bunch for esterification of palm fatty acid distillate (PFAD). Energy Convers. Manag., 195, 480-491. DOI: 10.1016/j.enconman.2019.05.022

[33] Tang, S., Wang, L., Zhang, Y., Li, S., Tian, S., Wang, B. (2012). Study on preparation of $\mathrm{Ca} / \mathrm{Al} / \mathrm{Fe}_{3} \mathrm{O}_{4}$ magnetic composite solid catalyst and its application in biodiesel transesterification. Fuel Process. Technol., 95, 84-89. DOI: 10.1016/j.fuproc.2011.11.022

[34] Junior, E.G.S., Justo, O.R., Perez, V.H., da Silva Melo, F., Reyero, I., Serrano-Lotina, A., Mompean, F.J. (2020). Biodiesel synthesis using a novel monolithic catalyst with magnetic properties $\left(\mathrm{K}_{2} \mathrm{CO}_{3} / \gamma-\mathrm{Al}_{2} \mathrm{O}_{3} /\right.$ Sepiolite $\left./ \mathrm{Y}^{-}-\mathrm{Fe}_{2} \mathrm{O}_{3}\right)$ by ethanolic route. Fuel, 271, 117650. DOI: 10.1016/j.fuel.2020.117650

[35] Engin, B., Demirtaş, H., Eken, M. (2006). Temperature effects on egg shells investigated by XRD, IR and ESR techniques. Radiat. Phys. Chem., 75, 268-277. DOI: 10.1016/j.radphyschem.2005.09.013
[36] Ali, R.M., Abd El Latif, M.M., Farag, H.A. (2015). Preparation and Characterization of $\mathrm{CaSO}_{4}-\mathrm{SiO}_{2}-\mathrm{CaO} / \mathrm{SO}_{4}{ }^{2-}$ Composite for Biodiesel Production. Am. J. Appl. Chem., 3, 38. DOI: 10.11648/j.ajac.s.2015030301.16

[37] Galván-Ruiz, M., Hernández, J., Baños, L., Noriega-Montes, J., Rodríguez-García, M.E. (2009). Characterization of Calcium carbonate, calcium oxide, and calcium hydroxide as starting point to the improvement of lime for their use in construction. J. Mater. Civ. Eng., 21, 694-698. DOI: 10.1061/(ASCE)08991561(2009)21:11(694)

[38] Ali, M.A., Al-Hydary, I.A., Al-Hattab, T.A. (2017). Nano-magnetic catalyst $\mathrm{CaO}-\mathrm{Fe}_{3} \mathrm{O}_{4}$ for biodiesel production from date palm seed oil. Bull. Chem. React. Eng. Catal., 12, 460468. DOI: $10.9767 /$ bcrec.12.3.923.460-468

[39] Li, F.J., Li, H.Q., Wang, L.G., Cao, Y. (2015). Waste carbide slag as a solid base catalyst for effective synthesis of biodiesel via transesterification of soybean oil with methanol. Fuel Process. Technol., 131, 421-429. DOI: 10.1016/j.fuproc.2014.12.018

[40] Liu, Y., Zhang, P., Fan, M., Jiang, P. (2016). Biodiesel production from soybean oil catalyzed by magnetic nanoparticle $\mathrm{MgFe}_{2} \mathrm{O}_{4} @ \mathrm{CaO}$. Fuel, 164, 314-321. DOI: 10.1016/j.fuel.2015.10.008

[41] Chieng, B.W., Lee, S.H., Ibrahim, N.A., Then, Y.Y., Loo, Y.Y. (2017). Isolation and characterization of cellulose nanocrystals from oil palm mesocarp fiber. Polymers, 9, 355. DOI: 10.3390/polym9080355

[42] Rao, B.V.S.K., Chandra Mouli, K., Rambabu, N., Dalai, A.K., Prasad, R.B.N. (2011). Carbon-based solid acid catalyst from de-oiled canola meal for biodiesel production. Catal. Commun., $14, \quad 20-26$. D O : 10.1016/j.catcom.2011.07.011

[43] Burhani, D., Putri, A.M.H., Waluyo, J., Nofiana, Y., Sudiyani, Y. (2017). The effect of two-stage pretreatment on the physical and chemical characteristic of oil palm empty fruit bunch for bioethanol production. AIP Conf. Proc., 1904, 020016. DOI: 10.1063/1.5011873

[44] Ullah, K., Ahmad, M., Sultana, S., Teong, L.K., Sharma, V.K., Abdullah, A.Z., Zafar, M., Ullah, Z. (2014). Experimental analysis of difunctional magnetic oxide catalyst and its performance in the hemp plant biodiesel production. Appl. Energy, 113, 660-669. DOI: 10.1016/j.apenergy.2013.08.023 
[45] Helwani, Z., Ramli, M., Saputra, E., Bahruddin, B., Yolanda, D., Fatra, W., Idroes, G.M., Muslem, M., Mahlia, T.M.I., Idroes, R. (2020). Impregnation of $\mathrm{CaO}$ from eggshell waste with magnetite as a solid catalyst $\left(\mathrm{Fe}_{3} \mathrm{O}_{4} / \mathrm{CaO}\right)$ for transesterification of palm oil off-grade. Catalysts, 10, 164. DOI: 10.3390/catal10020164
[46] Farrokheh, A., Tahvildari, K., Nozari, M. (2020). Biodiesel production from the Chlorella vulgaris and Spirulina platensis microalgae by electrolysis using $\mathrm{CaO} / \mathrm{KOH}-\mathrm{Fe}_{3} \mathrm{O}_{4}$ and $\mathrm{KF} / \mathrm{KOH}-\mathrm{Fe}_{3} \mathrm{O}_{4}$ as magnetic nanocatalysts. Biomass Convers. Biorefinery. DOI: 10.1007/s13399-020-00688-z 